details on pregnanediol tests and progesterone therapy in threatened and habitual abortion reference should be made to an article by $S$. Bender which appeared recently in the British Medical Journal $(1948,1,683)$ and to an annotation in the same issue (p. 696).

\section{Inheritance of Deformities}

Q.-Is termination of pregnancy justified in a case where the only child, now 11 years old, has gross congenital deformities? In the case $I$ have in mind the mother was normal until four weeks from term, when she developed generalized oedema. At birth there was a breech presentation with extended arms and legs; both fibulae were absent and there was valgus deformity of the feet. What is the likelihood of the mother giving birth again to a child with congenital abnormalities?

A.-This type of congenital deformity seems to occur sporadically, at least in the great majority of instances, and there seems to be little evidence that heredity is' a factor of importance. It is true that there appears to be a general tendency for a woman who has had a deformed child to have a somewhat increased chance of bearing another-not always with the same type of deformity. The increased risk is a small one, however, and the chance that the present pregnancy will result in a deformed child is probably not much greater than the 1 in 40 or so for any random pregnancy. The mother can be reassured that the odds are heavily on the side of the child, and in the writer's opinion abortion could not be justified on genetic grounds.

\section{Use of Detergent Solutions}

Q.-What is the usual composition of proprietary liquid detergents? Can you tell me if there is any danger in or contraindication to their use for the following purposes: (a) washing of dishes and other domestic utensils, and (b) personal ablution?

A. - It is not possible to discover the composition of a detergent which is a proprietary preparation. Many detergents, however, have similar properties, and it is a general rule that there is little danger from their use in washing dishes and utensils. For personal ablutions, however, they may give rise to dermatitis in sensitive subjects. Very severe dermatitis has followed the use of detergents as hair shampoos.

\section{Paronychia}

Q. Can you suggest any effective treatment for a woman, aged 42, with a chronic paronychia of $7 \frac{1}{2}$ months' duration? There is a slight discharge of pus containing staphylococci every month or so, and a kaolin poultice gives relief on these occasions, which are of short duration. In the intervals the skin around the nail-fold remains swollen and the nail has become wrinkled. Operation is not indicated.

A.- - If ringworm and monilia infection have been excluded as causes of the paronychia, treatment should aim at keeping the part dry, using radiant heat or short-wave diathermy locally or fractional doses of $x$ rays and the following paint:

$\mathrm{R}$ Mercury perchloride Brillia
Spirit

Make a paint.

An impaired peripheral circulation may play a part in the aetiology, in which case small doses of phenobarbitone and thyroid are helpful.

\title{
Adolescent Obesity
}

Q. - A girl of 18 has put on $1 \frac{1}{2}$ st. $(9.5 \mathrm{~kg}$.) in weight during the past twelve months. One sister (three years older) was obese when much younger; there is no other family tendency to obesity. There is little evidence of over-eating, except perhaps that she is a little too fond of sweets. Do girls in the late teens often tend to put on weight for a year or two? What investigations are necessary, and what is the most likely cause?

A.-It is more usual for the weight to be put on in the early teens-that is, at and after puberty-and for some of this to be lost in the later teens. The writer, who believes that adiposity is due to hyperactivity of the pituitary and adrenal glands rather than to any endocrine deficiency, considers that this increase in weight is associated with greater activity of the pituitary gland

at this phase in people of certain endocrine constitution. In the absence of other endocrine stigmata it is unlikely that investigations would reveal any gross lesion in this patient. Apart from an endocrine constitution as indicated above, one can only speculate on other causes, and that to no great purpose.

\section{Hot Flushes}

Q.-Is there any treatment for repeated hot flushes and sweats? A woman aged 53, who has had four children, was well until 1943, when her uterus was removed for fibroids. In 1944 she had acute rheumatism, which left her with mitral stenosis. Her blood pressure has gradually increased, until now it is about $200 / 105 \mathrm{~mm}$. The hot flushes and sweats average about thirty a day and leave her exhausted. No treatment has had any effect.

A.-It would be helpful to know what treatment has been tried. If the flushes and sweats are menopausal, as seems likely, they should respond to oestrogens. If they do not, then either the diagnosis is incorrect or previous oestrogen therapy may have been badly planned so that the patient has become resistant to it. Unless previously tried without effect, oestrogen should be given according to the usual technique, starting with the smallest possible dose which is sufficient to control rather than eliminate the flushes, and then gradually reducing this dose over the course of two or three months. Alternatively, empirical treatment with a-tocopherol, 60 to $100 \mathrm{mg}$. daily. or large doses of calcium, or small doses of thyroid, might be tried. The usual remedies for hypertension-rest and phenobarbitone, etc.-should be applied simultaneously. Symptoms of the kind described sometimes have a psychological basis.

\section{NOTES AND COMMENTS}

Unauthorized Quotation.-The solicitors to the Medical Defence Union have asked us to publish the following letter from Messrs. H. B. Wedlake Saint and Co.: "On behalf of our clients, Silten Limited, of Silten House, Hatfield, Herts, we refer to your letter of Sept. 24. Our clients have noted that you have been consulted by Professor L. S. P. Davidson and Dr. J. J. R. Duthie with regard to the use by our clients of your clients' names and the quotation from the section of the book on the treatment of rheumatic diseases, written by your clients, in connexion with our clients' preparation 'Leucotropin.' Our clients appreciate that it is considered grossly improper for a member of the medical profession to be associated with the sale of a proprietary remedy, and express their sincere regret that the pamphlet circulated by them gives the impression that your clients were advocating the use of our clients' preparation and are the authors of our clients' pamphlet. Our clients admit that the use of the names of your clients was unauthorized and fully apologize for the improper use of their names and the unauthorized quotation from the book written by your clients. Our clients undertake to withdraw the pamphlet from circulation forthwith and to destroy all pamphlets in their possession and to pay the costs incurred by your clients. Our clients have noted that your clients reserve to themselves the full right to publish this apology in the medical press or in such other manner as may be necessary to undo the harm which is likely to result to them from the improper use of their names."

Guide to the B.P.-British Drug Houses, Ltd., has recently published a new edition of its B.D.H. Guide to the B.P., 1948. It is available free to members of the medical profession. The purpose of the Guide is " to direct the attention of physicians and pharmacists to the alterations which have been made in the new Pharmacopoeia," with particular reference to the articles and preparations which are different from the corresponding ones in the 1932 B.P. and to those which have become official for the first time.

Correction.-In the letter from Dr. M. J. Fenton in the Journal of Oct. 16 (p. .723) there was a misprint in the name of the substance used for the treatment of burns-the correct name of the substance is silver dinaphthylmethane disulphonate. All communications with regard to editorial business should be addressed to THE TELEPHONE: EUSTON 2111. TELEGRAM: Aitiology, Westcent, London. ORIGINAL ARTICLES AND LETTERS forwarded for publi-at on are undorstood to be offered to the British Medical Journal alone. Authors desiring REPRINTS should communicate with the Publishing Manager, B.M A. House, Tavistock Square, W.C.1, on receipt of proofs. B.MERTISEMENTS stould B.M.A. House Tavistock Square, London, W.C.1 (hours $9 \mathrm{am}$. to 5 p.m.) B.M.A. House, Tavistock Square, London, W.C.1 (hours 9 a.m. to 5 p.m.). MEMBERS' SUBSCRIPT!ONS should be sent to the SECRETARY of the Association. EUSTON 2111. TELEGRAMS: Medisecra Westcent London. B.M.A. SCoTtish OFFICE: 7, Drumsheugh Gardens, Edinburoh. 